\title{
La industria cultural y su evolución a la industria creativa
}

\section{The Cultural Idustry and its evolution to the Creative Industry}

\author{
Esteban Rodríguez Torres \\ Facultad de Ciencias Sociales y Humanísticas \\ Universidad Máximo Gómez Báez, Ciego de Ávila, Cuba \\ https://orcid.org/0000-0002-3571-6899 \\ ert931025@gmail.com
}

\section{Referencia}

Rodríguez Torres, E. (2021). La industria cultural y su evolución a la industria creativa. Revista Guatemalteca de Educación Superior, 4(1), pp 72-82.

DOI: https://doi.org/10.46954/revistages.v4i1.55

Recibido: 15/11/2020

Aceptado: 16/01/2021

Palabras clave:

industria cultural, industrias

creativas, juventud

\section{Resumen}

La sociedad actual transita por nuevas prácticas en los procesos de consumo de las Industrias Creativas. Aunque toda la población mundial está bajo su influjo, la cultura digital ha moldeado las denominadas generaciones @ y la generación \# y sus prácticas de consumo, donde puede observarse un fuerte impacto en temas relacionados al consumo de audiovisual y el uso de las tecnologías para ello. El presente trabajo tiene como objetivo fundamental explicar cómo ha sido la evolución histórica de las Industrias Culturales a las Industrias Creativas.

\section{Abstract}

Today's society is going through new practices in the consumption processes of Creative Industries. Although the entire world population is under its influence, digital culture has shaped the 
so-called @ generations and \# generation and their consumer practices, where a strong impact can be observed on issues related to audiovisual consumption and the use of technologies for this. The main objective of this work is to explain how the historical evolution has been from Cultural Industries to Creative Industries.

\section{Introducción}

Con la llegada del siglo XXI el mundo se ha adentrado en una nueva era, denominada por muchos autores como era de las tecnologías o era digital. Esta se ha caracterizado por llevar a cabo todo un proceso del primer mundo llamado globalización. La globalización es un proceso de transformación que encierra variados aspectos de índole económico, tecnológico, político y cultural a nivel mundial que consiste en la progresiva trasmisión de la comunicación e interdependencia entre los disímiles países del globo terráqueo, logrando así unir sus mercados, sociedades y culturas, a través de una sucesión de alternativas a escalas sociales, económicas y políticas, pero sobre todo tecnológicas, ya que estas son el futuro de la humanidad.

Es por eso que con el surgimiento de las nuevas tecnologías la sociedad actual se ha visto transformada la vida cotidiana misma. Debido a las características propias que esta posee, el mundo del audiovisual y el entretenimiento ha pasado a ser en el ámbito de las industrias culturales e industrias creativas uno de los fenómenos más importantes, ya que prácticamente son indispensables en el modo de vida de las personas.

\section{Contenido}

\section{Industria Cultural, evolución a la Industria Creativa}

Toda comprensión del proceso de consumo implica el análisis de la Industria Cultural. Haciendo alusión a los autores Theodor Adorno y Max Horkheimer (1988) al expresar lo que se entiende por la Industria Cultural en las últimas décadas

\section{Keywords:}

Cultural Industry, Creative

Idustries, youth. 
del siglo XX, se puede manifestar que esta no es más que la habilidad de la economía capitalista, una vez perfeccionados diversos modos hábiles, para originar bienes culturales en forma escalonada y ascendente. En una ilustración más profunda, se puede expresar que es aquella parte de la economía que va evolucionando progresivamente en torno a bienes culturales y servicios culturales, como por ejemplo el mundo del arte, el entretenimiento, el diseño, la arquitectura, la gastronomía, y muchos más.

La aparición de dicho término es desarrollada por los autores de Frankfurt y se asocia a una de las reflexiones más profundas del pensamiento contemporáneo. Los diversos modos de saturación de masas por primera vez en la historia van a ser pensados no solo como elementos sustitutivos, sino como constitutivos del conflicto estructural de la sociedad, lo cual envuelve un devenir en profundidad de este aspecto: en vez de ir del estudio empírico de la masificación al de su sentido en la cultura. De hecho, entre los componentes más importantes de la concepción de Industria Cultural expresada por los autores Theodor Adorno y Max Horkheimer (1988) y haciendo alusión a estos se puede decir que estaba el trazar una imagen específica de la producción simbólica. Es importante mencionar que esta cuestión cultural se bautizaba por así decirlo en lugar importante desde el cual razonar las contradicciones de la sociedad.

Parafraseando a los autores (Horkheimer, \& Adorno, 1988, p.24) y expresando lo que ambos mencionan en este contexto se puede entender que la Industria Cultural se había desenvuelto con la superioridad del defecto de los pequeños matices sobre la obra, la cual una vez jugó un papel fundamental y fue el hilo conductor de una idea y que por tanto también había sido excluida junto con ésta. El fragmento, al independizarse, había adquirido una forma rebelde y se había levantado desde el movimiento romántico hasta el expresionista en expresión desligada en factor de la revolución contra la organización.

Como bien expresa el autor Barbero (1987) una vez que comienzan con la lógica que se extiende en el sistema tal y como puede ser examinado en el devenir de la industrializaciónmercantilización de la objetividad social para así poder llegar al 
estudio de la sociedad como consecuencia de los métodos de certificación y lugar de declaración de la cultura en que la lógica de la mercancía se llevaba a cabo. Por ende, la Industria Cultural puede ser explicada en términos tecnológicos. Esto se debe a la intervención en tal industria de un sinnúmero de personas lo cual traería como consecuencia que se impusieran técnicas de reproducción que a su vez llevarían a cabo que, en incontables lugares, necesidades idénticas fueran cubiertas por bienes standard o de grandes presupuestos.

Si analizamos lo expresado por el autor Barbero (1993) se puede manifestar que los bienes de la Industria Cultural pueden ser consumidos a niveles de rapidez extrema inclusive estando en un modo de poca concentración. Pero también se puede decir que cada uno de ellos es una guía del gran engranaje económico que protege a todos bajo un gran mandato desde sus inicios, en la labor y en el alivio que se le asimila. Según los autores mencionados anteriormente de cada filme sonoro, de cada transmisión radial se puede concluir aquello que no se podría traducir como efecto a ninguno de ellos apartadamente, pero si se analiza, sí al conjunto de todos en la sociedad. Irremediablemente, cada expresión desierta de la Industria Cultural reproduce a los seres humanos tal como aquello en que ya los ha transformado la gran Industria Cultural.

Parafraseando a los autores (Horkheimer \& Adorno, 1988, p.32) y resumiendo lo que ambos expresan se puede manifestar que la Industria Cultural, debido a sus tabúes, establece de forma positiva de la misma forma que su antítesis, el mundo del arte vanguardista, una frase propia con una sintaxis y un léxico de su autoría. Se puede ver como también se pone de manifiesto una necesidad intacta y real de diferentes bienes, los cuales siguen vinculados con los viejos esquemas, que a su vez no hacen más que aumentar con una autoridad de lo ya anteriormente establecido.

Por lo tanto, según los autores Theodor Adorno y Max Horkheimer (1988) la Industria Cultural viene a desencadenar una serie de procesos que no son apropiados para la sociedad, esta propicia de cierta manera que los valores y las cualidades positivas del hombre pasen a un segundo plano, centrándose solamente en un signo y una jerga mercantil. 
Resumiendo lo expresado por los autores (Horkheimer \& Adorno, 1988, p.38) se puede llegar a la conclusión que la Industria Cultural, en esencia, engloba la imitación y por tanto ha sido limitada a un puro estilo, ya que abandona el disfrazado secreto de éste, o sea, manifiesta su completo acatamiento a la jerarquía social. Según los autores mencionados anteriormente la crueldad estética asumida en ese momento amenaza los espacios espirituales desde el día en que comenzaron a ser recogidas y contrarrestadas como cultura.

Parafraseando al autor Raunig (2008) y lo que este expresa sobre los autores Theodor Adorno y Max Horkheimer (1988) se puede llegar a la conclusión que el resultado del trato entre el mecanismo y sus piezas lleva consigo que surja otro bloque de la definición de Industria Cultural, esto quiere decir que reside en el hecho de que los actores y los productores de cultura son empleados sometidos de las instituciones Industria Cultural. Según los autores Theodor Adorno y Max Horkheimer (1988), la manera corporativa en la cual se desempeña la Industria Cultural es la de las imponentes empresas de la música, el entretenimiento o los medios de comunicación de masas. Mencionan que los creativos se encuentran aislados dentro de una organización corporativa en la que su creatividad es agobiada bajo la forma del trabajo dependiente.

Resumiendo lo expresado por el autor (Raunig, 2008, p.39), el cual destaca que las recién nuevas industrias que se dedican al mundo de la creatividad (el ámbito de los periódicos, el cine, la radio y la televisión) se observa que logran acoplarse a los juicios de la fábrica fordista. Por lo que el carácter de cadena de acoplamiento decretó la elaboración creativa de la Industria Cultural de forma afín como lo había dispuesto antes con la agricultura y el trabajo del metal: mediante la estandarización y la completa autoridad de la creatividad.

Según lo manifestado por el autor Canclini (2001) en donde expresa que los autores Theodor Adorno y Max Horkheimer (1988), la Industria Cultural está impuesta por una sociedad irracional que es controladora de grandes capitales, ella se encarga de fijar todo lo que sale en el mercado: para el usuario 
no hay nada por catalogar que no haya sido ya adelantado en el esquematismo de la producción y de estos grandiosos supervisores del mercado. Se expresa que esta monumental corriente económica derivada de la Industria Cultural está mercantilizada de una forma muy disímil: o sea se puede evidenciar como el gigante norteamericano se queda con el $55 \%$ de las ingresos mundiales, la Unión Europea con el 25\%, Japón y Asia reciben el $15 \%$ y los países iberoamericanos solo cuentan con un $5 \%$.Es evidente por tanto la gran desventaja económica de América Latina, todo ello como resultado de la caída de sus gobiernos en el ámbito de la ciencia, tecnología y producción industrial de cultura, que a su vez condiciona nuestra baja competitividad a nivel mundial y la difusión restringida, solo dentro de cada nación, de la mayoría de libros, películas, videos y discos.

Si se analiza lo expresado por el autor (Raunig, 2008, p.34) se puede llegar a la conclusión de que el enfoque de quienes la consumen aparece en la representación de los autores claramente aislados de la de quienes la producen, aunque esta ausencia, sin embargo, no sea madurada como una imagen dualista en la que quien consume y quien produce constituyan correspondientemente los sujetos pasivos y activos dentro de la propia Industria Cultural. Aquellas personas que son consumidoras de la Industria Cultural florecen como títeres del capital contados, serializados, encarcelados en su mecanismo.

Parafraseando al autor (Raunig, 2008, p.33) podemos destacar que los interesados más frecuentes son obreros y empleados, agricultores y pequeños burgueses. La fundación pudiente los va intercomunicando de tal modo en cuerpo y alma que se doblegan sin oponer firmeza a todo lo que se les ofrece.

Por lo tanto es evidente ver como el consumo es tratado como mera reproducción, o sea, tan enmascarado que es capaz de brindarle a los consumidores lo que estos quieren, sin que estos logren percatarse de que en realidad están cayendo en una burbuja de cristal denominada consumismo. 
El significado crítico del término de "Industria Cultural" posteriormente fue entendida en múltiple y hace relato a una cadena de secciones concebidos como "culturales" en la condición de" Industrias Culturales" (arte en todas su manifestaciones, Medios de Comunicación, Moda, entre otras).

Realizando una valoración de lo expresado por el autor Canclini (2001) se puede arribar a la conclusión de que sin lugar a dudas, las Industrias Culturales han logrado convertirse en formas superiores de la formación de una pompa pública y la ciudadanía, como lugares de trasmisión de la búsqueda de información, sensibilización a las asuntos de utilidad común y discusión entre parcelas sociales. También se puede mencionar que desde el siglo XIX y aproximadamente hasta mediados del $X X$, estas funciones habían sido cumplidas por la literatura, el mundo de las artes visuales y la música, que facilitaron caudales para recapacitar sobre el principio de la nación, sobre el carácter individual de cada cultura y para fabricar los cruces de identidad.

Con la llegada del siglo XXI y la aparición de las nuevas tecnologías se habla de un mundo globalizado, el cual está regido por el avance de dichas tecnologías, por lo que se puede apreciar como ha ocurrido una trasformación en las Industrias Culturales, denominándose estas en la actualidad Industrias Creativas $^{1}$ donde el valor del producto está enmarcado según los intereses dominantes de la sociedad capitalista.

Según lo manifestado por (UNESCO, 2015, p.19) se puede resumir que en la actualidad la definición de Industrias Creativas debe su nacimiento al canje de cómo pensar las políticas culturales contemporáneas de algunos países anglosajones como el caso de Reino Unido de la Gran Bretaña, Australia y Nueva Zelanda). Todo esto con la intención de exigir al sector cultural en el plano mercantil y desarrollar sus procesos de hipermediación se lleva a cabo una circulación significativa de lo cultural a lo creativo.

1 En el Reino Unido emerge el término de "Industrias Creativas" para referir a una nueva forma de entender la cultura. 
También según lo expresado por (UNESCO, 2015, p.22). se puede resumir que esta fórmula viene a suceder una prolongada historia de la definición de Industrias Culturales que habían sido definidas anteriormente por los autores ya antes mencionados y que ahora incluirían todas aquellas industrias que producen y distribuyen bienes o servicios culturales, que deben ser apreciados desde el punto de vista de su aptitud, manejo y propósito específico, que representan o comunican expresiones culturales, independientes del valor productivo que puedan tener.

Parafraseando al autor Raunig (2008) se puede concluir que las Industrias Creativas constituyen un componente que con el de cursar del tiempo toman cada vez más importancia en las economías post-industriales las cuales están basadas en el conocimiento. Estas no solo ayudan al elevado crecimiento material y a la creación de empleos, sino que también se manifiestan como elementos que ayudan a la trasmisión de la identidad cultural, elemento ese que es de gran importancia para la promoción cultural. También expresa que durante la última década han sido muchos los gobiernos de diversas partes del mundo los que han comenzado a reconocer este hecho y han comenzado a raíz de esto a implementar políticas culturales específicas para darle promoción a dichas Industrias Culturales.

Además según lo expresado por el autor (Raunig, 2008, p.45) se puede evidenciar como a pesar de que ha existido un elevado interés, es cierto que el sector creativo es aún poco comprendido, todo esto debido a la mayoría de países que aún quedan por convencer con relación a este tema. Todo esto lleva a pensar que en los próximos años, sin duda alguna, la petición de recuentos más sofisticados se agrandará a nivel internacional, nacional y regional y los gobiernos deberán de posar y impulsar decisiones en este sector como un elemento clave en el desarrollo económico de sus estados.

Si analizamos lo expuesto por (UNESCO, 2015, p.12) podemos arribar a la conclusión de que esta es la única formación intergubernamental dedicada a la cultura y, por ende, ocupa un lugar centrado en el desarrollo seguro de metodologías estadísticas a nivel internacional. De esta manera, la UNESCO 
es la encargada de proveer a los gobiernos nacionales de las herramientas necesarias para lograr el estudio necesario en el sector de las Industrias Creativas, e insta a los países de todo el mundo a que este campo de investigación sea de gran prioridad.

Es importante destacar que en el mundo moderno en el cual se desenvuelve la sociedad actual, no se cuenta con un patrón internacional único para la obtención de indicadores estadísticos. Según datos recopilados en 1986, la UNESCO hizo público un marco de referencia Framework for Cultural Statistics (FCS), que por primera vez formó el intento íntegro por desarrollar una metodología común que permitiera obtener información sobre las actividades culturales.

La presente investigación asume el concepto según la (UNESCO, 2016, p. 12) sobre las Industrias Creativas la cual puede resumirse como "Aquellas determinadas divisiones de actividad establecida que tienen como fin fundamental la producción o la reproducción, la promoción, la difusión y/o la comercialización de bienes, servicios y actividades de contenido cultural, artístico o patrimonial".

Para concluir parafraseando al autor Canclini (2001) es necesario explicar que este punto de vista pone un énfasis no sólo en los servicios propios de la creatividad del ser humano que son reproducidos industrialmente, sino que da gran importancia a la cadena productiva y a las cargos específicos que realiza cada división para hacer llegar sus creaciones al público de manera general. Por lo que esta ilustración incluye a actividades relacionadas con la publicidad y el diseño gráfico, por citar un ejemplo, que contribuyen contundentemente a llevar a cabo este proceso.

Por ende según Canclini (2001) se puede arribar a la conclusión de que estas industrias son el "foco de la economía creativa", que a su vez forman parte de una tarea que encierra las esferas de economía, cultura y tecnología, focalizándose en la importancia de los servicios y del contenido creativo. Por consiguiente, existe una vinculación de la cultura con la economía gracias a estas Industrias Culturales, que mercantilizan el tiempo, la cultura y la experiencia de la vida y, por consiguiente, el consumo. 


\section{Conclusión}

Sin duda alguna en la actualidad las Industrias Creativas, exactamente el sector encargado del audiovisual y el entretenimiento, es hoy en día el que más aceptación posee por todo tipo de público en especial el de los jóvenes, ya que lo que rige el mundo en estos tiempos modernos son los avances tecnológicos y los jóvenes adquieren desde muy temprana edad esta práctica, llegando por lo tanto a transformarla y hacerla parte de su vida cotidiana.

\section{Referencias}

Barbero, J. M. (1987). Industria cultural: capitalismo y legitimación. Comunication Society.

Barbero, J. M. (1993). Industrias culturales: Modernidad e identidad.Comunication Society.

Canclini, N. (1992). Cine, televisión y video. Hábitos de consumo audiovisual en México. México. Proyecto de investigación.

Canclini, N. (2001). Por qué legislar sobre industrias culturales. Nueva Sociedad. $N^{\circ}$ 175. México. Proyecto de investigación.

Horkheimer, M. \& T. Adorno (1988). La industria cultural. Iluminismo como mistificación de masas. Buenos Aires: ADORNO, Theodor,

Raunig, G. (2008). La industria creativa como engaño de masas. AA. WV. Producción cultural y prácticas instituyentes, 2742.

UNESCO. (2015). Comprender las Industrias Creativas, las estadísticas como apoyo a las políticas públicas. Global Alliance for Cultural Diversity. 


\section{Sobre el autor}

\section{Esteban Rodríguez Torres}

Es Licenciado en Estudios Socioculturales en la Universidad Central Marta Abreu de Las Villas (UCLV), con 3 años de experiencia profesional en la enseñanza superior. Labora actualmente como docente de la Facultad de Ciencias Sociales y Humanísticas en la Universidad de Ciego de Ávila Máximo Gómez Báez, de Cuba y se encuentra en Formación de Maestría en Ciencias de la Educación Superior en su séptima edición.

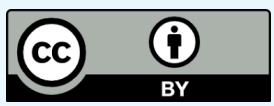

Este texto está protegido por una licencia CreativeCommons 4.0.

Usted es libre para compartir, copiar y redistribuir el material en cualquier medio o formato y adaptar el documento, remezclar, transformar y crear a partir del material para cualquier propósito, incluso comercialmente, siempre que cumpla la condición de atribución: usted debe reconocer el crédito de una obra de manera adecuada, proporcionar un enlace a la licencia, e indicar si se han realizado cambios. Puede hacerlo en cualquier forma razonable, pero no de forma tal que sugiera que tiene el apoyo del licenciante o lo recibe por el uso que hace. 